\title{
Filogenia y oncogénesis del virus del papiloma humano: una aproximación translacional al descubrimiento de biomarcadores para la detección de lesiones precancerosas de cérvix
}

\author{
Arianis Tatiana Ramírez-Pineda ${ }^{1}$, Martha Isabel González ${ }^{\mathbf{1}}$, Kelly Melisa Castañeda-Vanegas ${ }^{\mathbf{1}}$, \\ María Cecilia Agudelo-Fernández ${ }^{1}$, Carolina López-Urán², Gloria Inés Sánchez-Vásquez ${ }^{1, *}$ \\ ${ }^{1}$ Grupo de Infección y Cáncer, Facultad de Medicina, Universidad de Antioquia, Medellín, Colombia \\ ${ }^{2}$ Departamento de Patología, Facultad de Medicina, Universidad de Antioquia, Medellín, Colombia
}

Artículo de posesión para el ingreso como miembro correspondiente a la

Academia Colombiana de Ciencias Exactas, Físicas y Naturales el 23 de julio del 2019

\begin{abstract}
Resumen
El cáncer cervical es la principal causa de mortalidad entre las mujeres en poblaciones con índice de desarrollo humano bajo y medio. La infección con 14 de los genotipos del virus del papiloma humano de alto riesgo (VPH-AR) es la causa principal de este cáncer. Las vacunas profilácticas previenen esta infección si se aplican antes del inicio de la actividad sexual. Las mujeres que no han sido vacunadas deben someterse a tamización con la prueba de VPH-AR, y recibir el diagnóstico histopatológico y el tratamiento oportunos. Cerca del $20 \%$ de las mujeres son positivas para el VPH-AR, pero muy pocas presentan lesiones potencialmente malignas. Las mujeres infectadas con los genotipos VPH16 o 18 o aquellas con ascendencia europea infectadas con variantes de origen nativo americano del VPH 16 tienen mayor riesgo de cáncer. También aquellas con historia de uso de anticonceptivos hormonales y de tabaquismo. Estos factores parecen contribuir a un aumento de la expresión de las oncoproteínas E6 y E7 del VPH-AR, lo que conduce a la desregulación del control del ciclo celular y, finalmente, al cáncer. En el presente estudio se pasa revista al estado del arte de los mecanismos carcinogénicos del VPH-AR haciendo énfasis en el papel de las proteínas E6 y E7 y se presentan los resultados de la genotipificación del VPH16 o 18, la tasa de positividad de las proteínas p16 y ki67 y la evaluación bioinformática de la expresión aberrante de los miARN y su correlación con el grado de la lesión cervicouterina, datos que contribuyen a validar el potencial clínico de estos biomarcadores para la detección de lesiones potencialmente malignas de cérvix.
\end{abstract}

Palabras clave: Virus del papiloma humano; Variantes virales; Filogenética; Cáncer cervical; Biomarcadores; Prevención secundaria.

Phylogeny and oncogenicity of the human papillomavirus: A translational approach for the discovery of biomarkers for the detection of precancerous lesions of the cervix

\begin{abstract}
Cervical cancer is the main cause of mortality among women in populations with low and medium human development index. The infection with 14 genotypes of the high-risk human papillomavirus (HR-HPV) is the main cause of this cancer. Prophylactic vaccines prevent this infection if they are applied before the onset of sexual activity. Unvaccinated women should be screened with the HR-HPV test and receive the histopathological diagnosis and timely treatment. About $20 \%$ of women are HR-HPV positive, but very few have potentially malignant lesions. Women infected with HPV16 or 18 genotypes or women with European ancestry infected with Native American variants of HPV 16 have a higher risk of cancer. Also, those with a history of use of hormonal contraceptives and cigarette smoking. These factors seem to contribute to an increase in the expression of the HR-HPV oncoproteins E6 and E7, which leads to the deregulation of cell cycle control and finally to cancer. We present here the state of the art of the carcinogenic mechanisms of HPV-AR emphasizing the role of the E6 and E7 proteins, as well as the results of our study on the HPV16 or 18 genotyping, the positivity rate of the p16 and ki67 proteins, and the bioinformatic evaluation of the aberrant expression of miRNAs and their correlation with the degree of cervical lesions. These data contribute to validate the clinical potential of these biomarkers for the detection of potentially malignant lesions of the cervix.
\end{abstract}

Key words: Human papillomavirus; Viral variants; Phylogenetic; Cervical cancer; Biomarkers; Secondary prevention.

*Correspondencia:

Gloria Inés Sánchez-Vásquez; sanchezg@une.net.co, Recibido: 15 de noviembre de 2018, Aceptado: 11 de marzo de 2019, Editor: Juana Ángel 


\section{Introducción}

El cáncer cervical es una neoplasia maligna que se produce a partir de la alteración de las células del cérvix. El cérvix es el único órgano del aparato genital femenino que está conformado por dos tipos de epitelio: el exocervical, que es plano, y el endocervical, cilíndrico y mucosecretor. El sitio de unión de estos dos epitelios se llama unión escamocolumnar o zona de transformación, y su localización varía durante la vida de la mujer debido a los cambios metaplásicos en el epitelio cervical, los cuales ocurren después de la pubertad y durante el embarazo. La metaplasia es el nombre dado al proceso por el cual un tipo de epitelio completamente diferenciado se transforma en otro, lo que en el cuello uterino implica la transformación del epitelio endocervical en un epitelio escamoso. Este fenómeno fisiológico predispone a dichas células al desarrollo de cáncer por la acción de la infección por el virus del papiloma humano de alto riesgo (VPH-AR) (Herfs, et al., 2012). Los dos tipos histológicos principales de cáncer de cuello uterino reconocidos por la Organización Mundial de la Salud (OMS) son el escamocelular y el adenocarcinoma, originados en las células del exocérvix y el endocérvix, respectivamente. El primero constituye cerca de 80 a $85 \%$ de todos los casos, mientras que el adenocarcinoma constituye entre 10 y $12 \%$ (Eroschenko, 2008).

La infección por el VPH se adquiere con el inicio de las relaciones sexuales; en la gran mayoría de los casos $(70 \%$, aproximadamente) se presenta una infección autocontrolada que se resuelve en un plazo de 18 meses (Rodríguez, et al., 2008). Ocasionalmente, dicha infección puede inducir una lesión intraepitelial de bajo grado (NIC1); sin embargo, estas lesiones regresan espontáneamente en la mayoría de los casos. Cuando el virus no se elimina y persiste la infección por VPH-AR, la lesión precursora se mantiene y entre un 5 y un $10 \%$ de estas lesiones puede progresar hasta convertirse en una lesión intraepitelial de alto grado, o mayor (neoplasia intraepitelial cervical de grado 2 o NIC2+), que si no es tratada a tiempo, progresa a cáncer (Rodríguez, et al., 2008).

Carga de la enfermedad. El cáncer cervical es la cuarta causa más frecuente de cáncer entre las mujeres alrededor del mundo, y la primera en muchos países con un índice de desarrollo humano bajo o medio, donde ocurre cerca del $80 \%$ de los casos y muertes reportadas anualmente (Bray, et al., 2018). En el 2018, el Global Cancer Observatory (GLOBOCAN) estimó en 570.000 los nuevos casos y en 311.000 las muertes, con una tasa de incidencia y mortalidad estandarizada por edad de 13,1 y 6,9 por cada 100.000 mujeres, respectivamente (Bray, et al., 2018). En los países de menor índice de desarrollo humano este cáncer ocupa el segundo lugar en incidencia después del cáncer de mama y el primero en mortalidad. En 28 países es el cáncer que se diagnóstica con más frecuencia, y en otros 42 es la primera causa de muerte. La gran mayoría de estos países están ubicados en África y Asia. En América Latina y el Caribe este cáncer ocupa la tercera posición entre los cánceres que se presentan entre las mujeres; en el 2018 se reportaron 56.186 casos nuevos y 28.318 muertes, con una tasa de incidencia y mortalidad estandarizada por edad de 14,6 y 7,1 por cada 100.000 mujeres, respectivamente. En Colombia ocupa la cuarta posición entre los cánceres que se presentan en las mujeres, con un total de 3.900 casos nuevos y 1.800 muertes en ese mismo año, y una tasa de incidencia y mortalidad ajustadas por edad de 12,7 y 5,7, respectivamente (Bray, et al., 2018).

La inequidad contribuye enormemente a que las mujeres desarrollen cáncer de cérvix y representa el mayor desafío para la salud de aquellas que viven en estas regiones.

Caracterización clínica de las lesiones potencialmente malignas del cuello uterino. El desarrollo del cáncer de cuello uterino se manifiesta inicialmente a la manera de lesiones precursoras conocidas como neoplasia intraepitelial cervical, habitualmente de evolución lenta y progresiva, generalmente en estadios. Convencionalmente, los estadios se denominan NIC1, NIC2 y NIC3, según la cantidad de epitelio cervical que se encuentre comprometido (Figura 1). Microscópicamente, la evolución de la lesión se caracteriza por la proliferación de las células epiteliales que progresivamente invaden el espesor del epitelio. Conforme se incrementa la gravedad de la neoplasia intraepitelial cervical aumenta el número de figuras mitóticas, visibles en las capas epiteliales superficiales (Zsemlye, 2013).

La neoplasia intraepitelial cervical de grado 1 (NIC1), o bajo grado, es la consecuencia más frecuente de una infección productiva por el VPH humano y en ella las células presentan una buena maduración y solo en el tercio inferior se observan células indiferenciadas y pocas figuras mitóticas. Pueden verse, además, efectos citopáticos virales (coilocitos), los cuales corresponden a la manifestación clásica de la infección por VPH en la célula cervical. Las lesiones NIC2 o displasia de alto grado, se caracterizan por cambios celulares displásicos restringidos a los dos tercios inferiores del epitelio, y la atipia nuclear es más grave que en las lesiones NIC1. Pueden verse figuras mitóticas en toda la mitad inferior del epitelio, pleomorfismo en el núcleo y pérdida de la polaridad celular (Zsemlye, 2013). En las lesiones NIC3 hay una mayor pérdida de maduración, el epitelio inmaduro ocupa todo el espesor del epitelio, la diferenciación y la estratificación se pierden por completo en toda la superficie epitelial y se encuentran abundantes figuras mitóticas anormales. Esta lesión precede al cáncer cervical y, al igual que las NIC2, deben ser tratadas para evitar que progresen hasta un cáncer cervical (Figura 1) (Zsemlye, 2013).

Etiología. La etiología del cáncer cervical ha sido claramente demostrada en estudios moleculares in vitro y plenamente confirmada en estudios epidemiológicos. Esta infección cumple con los criterios de causalidad de Bradford Hill, y la infección por VPH-AR se considera la causa necesaria para el desarrollo del cáncer de cuello 


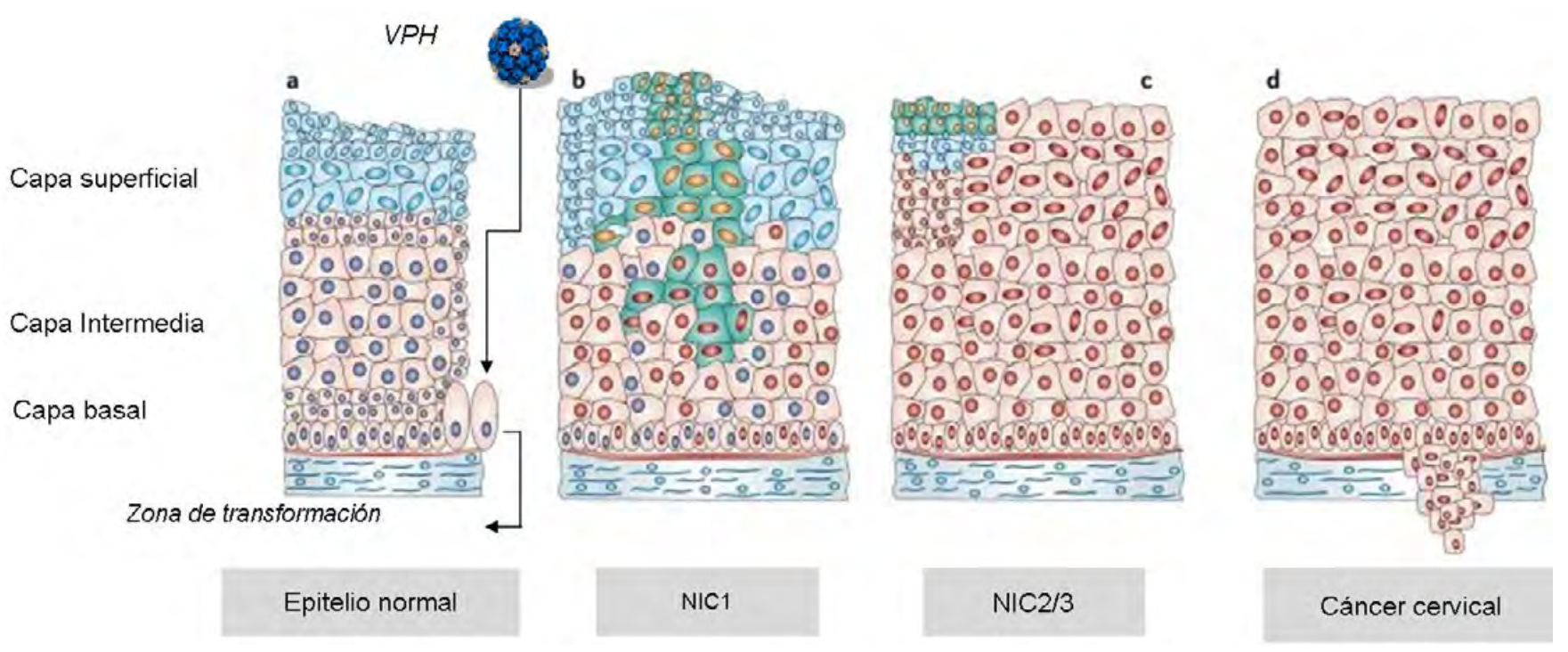

Figura 1. Representación esquemática de las lesiones causadas por el VPH en el epitelio cervical

a) El VPH ingresa por micro heridas al epitelio cervical normal; la zona de transformación es el sitio donde más comúnmente se inician las infecciones virales y el desarrollo de lesiones cervicales. b) Después del inicio de la infección, el ADN viral se replica e inicia la expresión de genes virales (células con núcleo rojo), hasta tal punto que si la infección no remite, empiezan a surgir anormalidades en el primer tercio inferior del epitelio. c) Si la infección persiste, las alteraciones celulares ocuparan las dos terceras partes del epitelio en NIC2, y todo el espesor del epitelio en NIC3. d) Si no se instaura el tratamiento adecuado la proliferación descontrolada de estas células induce el rompimiento de la membrana basal y se inicia en este punto el desarrollo del cáncer cervical. La figura fue tomada y modificada de Roden \& Wu, 2006. Todos los derechos reservados

uterino (Bosch, et al., 2002; Walboomers, et al., 1999). Los hallazgos más significativos en la comprobación de dicha relación causal son la demostración de la función de transformación celular de los oncogenes E7 y E6 mediante el bloqueo de las proteínas supresoras de tumores $\mathrm{pRb}$ y $\mathrm{p} 53$, respectivamente, y los estudios de casos y controles que demostraron que son 14 tipos del VPH-AR los que se asocian de forma exclusiva con el riesgo de este cáncer. Estos 14 genotipos se distribuyen en dos grupos filogenéticos caracterizados por la alta afinidad de sus oncoproteínas E7 y E6 por la pRb y la p53, respectivamente, lo que evidencia claramente la relación epidemiológica y filogenética de la oncogénesis del VPH (Muñoz, et al., 2003; Schiffman, et al., 2005). Estos 14 genotipos de VPH-AR son los únicos capaces de inducir infección persistente, la cual es el primer requisito para la carcinogénesis cervical. Sin embargo, existen otros factores concomitantes relacionados con el ambiente y el huésped que pueden modular la persistencia y la progresión maligna. Entre estos factores se encuentran las inmunodeficiencias adquiridas (infección por VIH, tratamientos inmunosupresores) o congénitas (respuestas inmunológicas anormales, tipos HLA y polimorfismos en p53); factores hormonales como el uso prolongado de anticonceptivos orales, el tabaquismo, las infecciones concomitantes con otros agentes infecciosos como el virus herpes simplex de tipo 2 (VHS-2), con Chlamydia trachomatis y el virus de Epstein Bar (VEB), así como los múltiples partos (Muñoz, et al., 2006).
Virus del papiloma humano. Los VPH son virus pequeños con un genoma de ADN circular de doble cadena de aproximadamente 8.000 pares de bases de longitud y una cápside de simetría icosahédrica sin envoltura, que pertenecen a la familia Papillomaviridae.

Estos virus tienen especificidad celular, y solo infectan células del epitelio escamoso, cutáneas o mucosas, dando lugar a lesiones proliferativas de origen epitelial (Doorbar, et al., 2015). Las partículas virales miden entre 52 y $55 \mathrm{~nm}$ de diámetro. La cápside está constituida por 72 capsómeros pentaméricos de la proteína $\mathrm{L} 1$, que es la proteína tardía más abundante de la cápside (representa el $95 \%$ ) y de la proteína L2, que representa tan solo el $5 \%$ de la cápside; esta última se asocia internamente a los capsómeros formados por L1 (Finnen, et al., 2003). En el interior de la cápside se encuentra el genoma viral, que comprende tres regiones funcionales ubicadas en una de las cadenas del ADN circular, como se observa en la figura 2. La primera región se conoce como reguladora o región larga de control (Long Control Region, LCR), la cual contiene el origen de la replicación y los sitios de unión para factores de transcripción viral y celular, y, asimismo, cumple una función reguladora de la transcripción de los genes virales E6 y E7 (Van Doorslaer, 2013). La segunda es una región temprana (E del inglés Early), que contiene seis marcos de lectura abiertos (open reading frame, ORF), conformada por los genes E1, E2, E4, E5, E6, y E7, los cuales codifican para proteínas no estructurales involucradas en la transcripción, replicación 


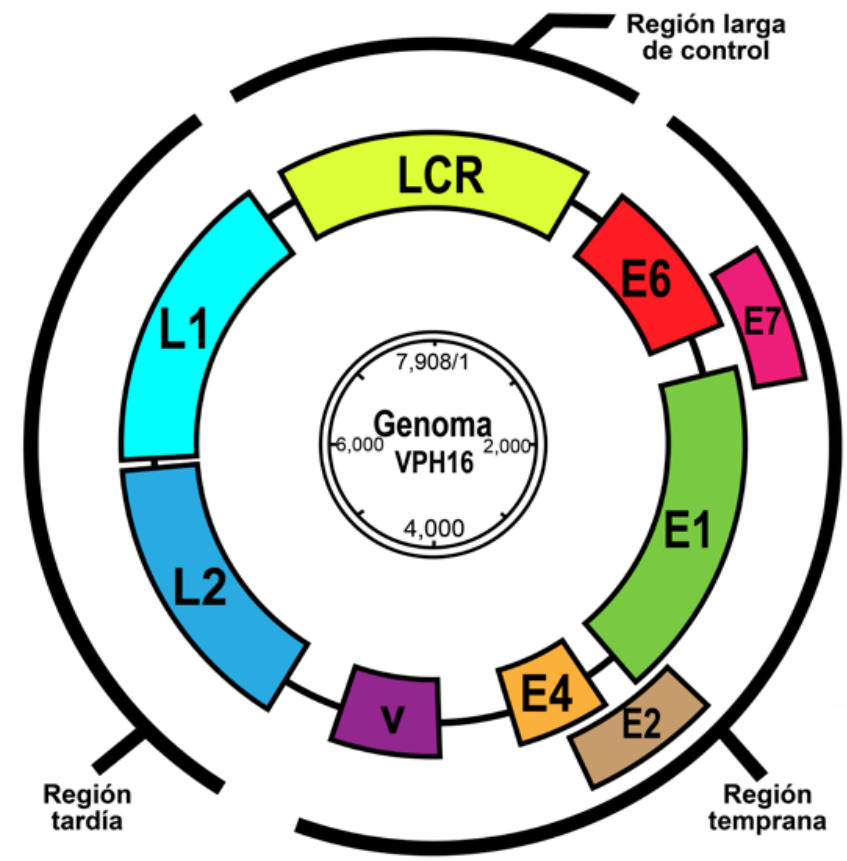

Figura 2. Estructura y organización del genoma de VPH tipo 16. El esquema representa la molécula de doble cadena circular, dividida en sus tres regiones principales: región reguladora (LCR), región temprana (Early) y región tardía (Late). Imagen elaborada por las autoras.

y oncogénesis viral; dicha región se localiza en posición adyacente y corriente abajo del LCR. La tercera es la región tardía (L, del inglés Late), ubicada en posición adyacente y corriente abajo de la región temprana, la cual codifica las proteínas estructurales de la cápside L1 y L2, facilitadoras del empaquetamiento y la maduración del ADN viral (Van Doorslaer, 2013).

Se han caracterizado y secuenciado más de 150 papilomavirus humanos, y se conoce que, de estos, alrededor de 40 tipos pueden infectar los órganos genitales, incluido el cuello uterino, la vagina, la vulva, el pene y el ano. Los tipos virales capaces de infectar las mucosas se dividen en virus de alto riesgo (VPH-AR) y bajo riesgo (VPH-BR), según si presentan propiedades que puedan llevar al desarrollo de cáncer (Doorbar, et al., 2015; Muñoz, et al., 2003). Los VPH-BR no son oncogénicos y clínicamente producen lesiones benignas (verrugas genitales o condilomas); VPH6 y VPH11 son los principales tipos virales asociados con estas lesiones. Por el contrario, los VPH-AR son clasificados como virus oncogénicos, y se asocian con el desarrollo de lesiones potencialmente malignas y con el cáncer de cuello uterino. En este grupo, VPH16 y VPH18 son los más importantes, dado que son los responsables de aproximadamente el $70 \%$ de todos los casos de cáncer de cuello uterino.

Clasificación taxonómica. Como ya se mencionó, la clasificación taxonómica revela una mayor cercanía filogenética, la cual explica no solo sus características biológicas sino también patogénicas. Es así como los tipos VPH6 y VPH11 se han clasificado en la especie 10 conjuntamente con otros tipos virales asociados unicamente con lesiones benignas. Mientras que VPH16 se clasifica en la especie 9 con los tipos virales VPH31, VPH33, VPH52, entre otros, los cuales están asociados con el desarrollo de cáncer. Los virus del papilloma se ubican taxonómicamente en la familia Papillomaviridae, que contiene 16 géneros, los cuales son designados con una letra griega como prefijo y con la terminación papillomavirus, así: $\alpha$-papillomavirus, $\beta$-papillomavirus, $\gamma$-papillomavirus, entre otros (de Villiers, et al., 2004). La clasificación taxonómica del VPH se basa en las diferencias encontradas en la secuencia de nucleótidos del ORF que codifica para la proteína de la cápside L1, una de las regiones más conservadas del genoma viral (de Villiers, et al., 2004). Los tipos de VPH que pertenecen a diferentes géneros presentan una variación dentro de la región L1 del genoma viral de más del $40 \%$. Para la clasificación en diferentes especies virales, debe haber un porcentaje de variación entre 30 y $40 \%$ en esta misma región. La clasificación de un nuevo tipo de VPH se define si el genoma completo ha sido secuenciado y la secuencia de nucleótidos del gen L1 difiere por lo menos en un $10 \%$ de la de cualquier otro tipo caracterizado. Si la variación en la secuencia de nucleótidos está entre el 1 y el $10 \%$, se considera una variante o linaje viral, y si está entre 0,5 y $1,0 \%$, como un nuevo sublinaje (de Villiers, et al., 2004).

Variantes del VPH y riesgo de cáncer de cuello uterino. En diversos estudios se ha reportado que la variación genética de VPH16 está asociada con la persistencia y el riesgo de cáncer de cuello uterino (Berumen, et al., 2001; Cornet, et al., 2013; Sánchez, et al., 2011). En el caso del VPH16, tipo viral asociado con el $50 \%$ de los casos de cáncer cervical, se han identificado cuatro variantes o linajes filogenéticos (A, B, C y D) que incluyen al menos nueve sublinajes, los cuales se han nombrado según los grupos étnicos donde se han descrito con mayor frecuencia: los sublinajes A1, A2 y A3 corresponden a las variantes europeas (E), A4 a las asiáticas (AS), B1 a las africanas-1a (Afr1a), B2 a las africanas-1b (Afr1b), D1 a las norteamericanas 1 (NA), D2 a las asiático-americanas 2 (AA2), D3 a la asiático-americana 1 (AA1), y el linaje $\mathrm{C}$ a la africana-2a (Afr2a) (Burk, et al., 2013).

Existe una diferencia en la distribución de estas variantes entre las áreas geográficas del mundo (Yamada, et al., 1997) y los diferentes grupos étnicos (Vargas-Robles, et al., 2018), lo cual se confirmó con la identificación de variantes genéticas en 953 muestras positivas para el VPH16 recolectadas por la Agencia Internacional de Investigaciones sobre el Cáncer (International Agency for Research on Cancer, IARC) en 17 países del norte de África y del África subsahariana, Asia oriental y occidental, Europa (Georgia, Polonia y España) y en muestras de Suramérica (Cornet, et al., 2012). Se encontró que las variantes E se distribuyen uniformemente en todas las regiones del mundo, 
y las variantes AS, AA y Af (no europeas) se han registrado fundamentalmente en Asia oriental, las Américas y las regiones africanas, respectivamente (Cornet, et al., 2013).

La infección con variantes no europeas (Af1, Af2, AA, AS, NA) se ha asociado con un riesgo dos a nueve veces mayor de cáncer cervical que las variantes E, especialmente en estudios llevados a cabo en Estados Unidos y Latinoamérica (Berumen, et al., 2001; Burk, et al., 2003; de Boer, et al., 2004; Hildesheim, et al., 2001; Tornesello, et al., 2004). Las poblaciones europeas presentan infección predominantemente con variantes $\mathrm{E}$; específicamente la variación en la posición $350 \mathrm{~T}$ en comparación con la $350 \mathrm{G}$ del gen E6 del VPH16 tienen dos veces más de riesgo de persistencia (Cornet, et al., 2013).

Asimismo, los sublinajes A4, C, D2 y D3 presentan un riesgo de lesiones precancerosas y de cáncer significativamente mayor en comparación con los sublinajes A1/A2 en Estados Unidos (Mirabello, et al., 2016). En este estudio se encontró que aquellas mujeres cuya raza o etnia coincidía con la variante infecciosa del VPH16 tenían un mayor riesgo de ser positivas para lesiones de estadio NIC3. Por el contrario, en estudios anteriores llevados a cabo por nuestro grupo de investigación no se encontró evidencia de la correspondencia con esta variante (raza o etnia) (Lopera, et al., 2014). Mediante métodos aún más afinados para definir la ascendencia genética se observó una correlación inversa en la distribución de las proporciones de la ascendencia y la frecuencia de esta variante. Se encontró que las mujeres con cáncer cervical con una mayor proporción de ascendencia europea o nativo americana presentaban las variantes AA o E en mayor proporción. Esta relación entre la ascendencia y la distribución de los linajes filogenéticos sugiere que la evolución concertada de la población humana y algunos de los sublinajes específicos del VPH16, se han traducido en la potenciación de propiedades carcinogénicas virales o en la disminución de la capacidad del huésped de controlar la infección, lo que explicaría que el riesgo de lesiones potencialmente malignas y de cáncer de cuello uterino se dé solo en un reducido porcentaje de la población mundial.

Es importante aclarar que los estudios de asociación epidemiológica no necesariamente se traducen en una correlación etiológica mecánica o molecular y que deben explorarse más los mecanismos moleculares que pudieran explicar esta asociación, dado que las características bioquímicas de las oncoproteínas virales que se traducen a partir de estas variantes es limitada.

Estructura y variabilidad de las proteínas oncogénicas E6 y E7 del VPH. La proteína E6 del VPH está conformada aproximadamente por 150 aminoácidos altamente conservados, pues contiene dos motivos o dedos de zinc muy conservados que se caracterizan por la presencia de cuatro motivos Cys-X-X-Cys, cuya integridad es esencial para su interacción con diversas proteínas de la célula huésped (Vande Pol \& Klingelhutz, 2013). En el extremo C-terminal la proteína E6 tiene el motivo $\mathrm{X}-(\mathrm{T} / \mathrm{S})-\mathrm{X}-(\mathrm{V} / \mathrm{I} / \mathrm{L})$, que se conserva entre los VPH-AR y que se une a la familia de las proteínas PDZ. La proteína E6 es esencial para el ciclo productivo del virus y el mantenimiento del ADN viral en los queratinocitos y presenta actividades oncogénicas claramente descritas; además, se une a un sinnúmero de blancos celulares, entre los que se encuentran la proteína supresora de tumores $\mathrm{p} 53$, las proteínas con dominios PDZ y la telomerasa. La unión de E6 con la proteína p53 induce su degradación por la vía de la ubiquitina, lo que le permite bloquear la apoptosis, interferir con la diferenciación celular e inducir la transformación celular en las células infectadas (Vande Pol \& Klingelhutz, 2013). También se ha reportado que la E6 puede interrumpir la apoptosis mediante mecanismos independientes de la p53, uniéndose a Bak (una proteína pro-apoptótica de la familia Bcl-2) (Vande Pol \& Klingelhutz, 2013).

La proteína E6 induce, además, la degradación de la proteína humana PDZ hDlg, la cual está involucrada en la formación de uniones celulares, la regulación de la adhesión celular y la proliferación de los tejidos epiteliales. Esta alteración induce una desregulación en el control del crecimiento invasivo de las células epiteliales, favoreciendo la formación e invasión del tumor maligno (Pim \& Banks, 2010).

Además de unirse a la telomerasa y activar la transcripción de la subunidad catalítica de esta enzima, lo cual ayuda al mantenimiento de las estructuras teloméricas contenidas al final de los cromosomas, permite la proliferación celular sostenida (Vande Pol \& Klingelhutz, 2013), e interfiere con la respuesta inmunológica ante la infección viral. La proteína E6 tiene una función inmunosupresora mediante su unión al transactivador de transcripción IRF-3, afectando su función de activador transcripcional, lo que directamente interrumpe la expresión de los genes inducidos por el interferón. Además, se une a la proteína tirosina cinasa 2 (tyrosine-protein kinase 2, Tyk2), una proteína transductora de señales de la vía Jak-STAT y, por lo tanto, interfiere en la activación de la vía de señalización del IFN- $\alpha$ (Vande Pol \& Klingelhutz, 2013). La otra oncoproteína del VPH es la E7, la cual está conformada por cerca de 100 aminoácidos y posee un sitio con motivos de dedos de zinc en su extremo carboxilo terminal, el cual se utiliza para su dimerización (Roman \& Munger, 2013); en la región amino terminal la E7 contiene dos regiones homólogas con la proteína E1A del adenovirus; estos dominios son importantes para la actividad transformadora, pues permiten la interacción con diferentes proteínas celulares, incluidas la unión y la degradación de la proteína supresora de tumores del retinoblastoma $(\mathrm{pRb})$, lo que contribuye a la progresión maligna y la inducción de la inestabilidad genómica en las células infectadas (Roman \& Munger, 2013). En una primera instancia, la proteína E7 establece un complejo con la forma hipofosforilada de $\mathrm{pRb}$ e induce su degradación. La inactivación de $\mathrm{pRb}$ induce, a su vez, la activación constitutiva del factor de transcripción E2F, que, en su turno, induce la activación de genes involucrados en la síntesis de ADN durante la fase S del ciclo celular (Roman \& Munger, 2013). 
Otra característica de la proteína E7 es su capacidad de unión a miembros de la familia de factores de transcripción AP-1, tales como c-Jun, JunD y c-Fos, todos ellos importantes en las vías de señalización relacionadas con el proceso de mitosis y de diferenciación celular (Antinore, et al., 1996). Las proteínas que pertenecen al grupo Jun controlan la proliferación y la apoptosis mediante su capacidad de controlar la expresión y la función de los reguladores del ciclo celular. La E7 se une a c-Jun y activa su promotor por un mecanismo de transactivación, potenciando la activación de genes involucrados en la progresión del ciclo celular y la mitosis (Antinore, et al., 1996). Por último, esta proteína también puede interactuar con el factor de crecimiento semejante a la insulina 3 (insulin-like growth factor binding protein 3, IGFBP-3) modulando el proceso de apoptosis (Roman \& Munger, 2013).

La desregulación del ciclo celular por acción de las proteínas E6 y E7 predice el riesgo de cáncer cervical. Como ya se mencionó, las proteínas E6 y E7 son esenciales para la capacidad transformadora de los VPH-AR mediante la interferencia con las funciones de los supresores de tumores p53 y pRb, respectivamente, lo que impide la regulación de los principales puntos de control del ciclo celular (Vande Pol \& Klingelhutz, 2013). La cooperación entre estas dos oncoproteínas conduce a la inmortalización celular in vitro, en la cual la célula no solamente es incapaz de eliminar el ADN viral, sino que pierde la capacidad de corregir errores intrínsecos en el $\mathrm{ADN}$, de modo que se van acumulando alteraciones genéticas progresivamente hasta convertirse en una célula con fenotipo neoplásico (Yeo-Teh, et al., 2018). Uno de los hallazgos clínicos más importantes es que los niveles de expresión de las oncoproteínas E6 y E7 del VPHAR, pero no así las del VPH-BR, aumentan con la gravedad de la lesión, expresión que se correlaciona con el grado de las lesiones histológicas. En las lesiones NIC1 o de bajo grado, el ciclo viral permisivo y productivo se acompaña de la replicación completa del genoma y la liberación de nuevos viriones de las células escamosas diferenciadas del epitelio. Sin embargo, cuando la infección se convierte en persistente, se produce un aumento en la expresión de E6 y E7, lo que conduce al desarrollo de lesiones $\mathrm{NIC} 2+$ o del alto grado. En este tipo de infecciones el nivel de expresión de E6 y E7 es más alto y, además, la producción de partículas virales baja (Doorbar, et al., 2012), así como la expresión aberrante de proteínas reguladoras del ciclo celular, como la p16INK4a (p16), codificada por el gen supresor de tumores CDKN2A (Bergeron, et al., 2015). Como se explica en la figura 3, en una célula normal en la cual se ha inducido el estado proliferativo, la transición de la fase G1 a S del ciclo celular es activada directamente por una serie de heterodímeros formados por las ciclinas y las cinasas dependientes de ciclinas (cyclin-dependent protein kinases, CDK), específicamente, por los complejos ciclina D/CDK4/6 y ciclina $\mathrm{E} / \mathrm{CDK} 2$. La función del complejo D/CDK4/6 es fosforilar

\section{A. Célula no infectada}

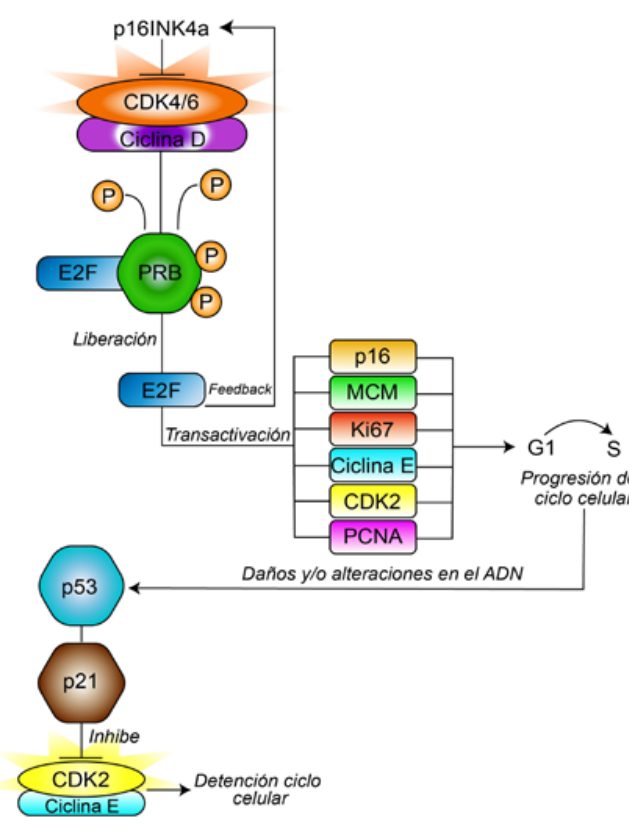

B. Célula infectada con VPH AR

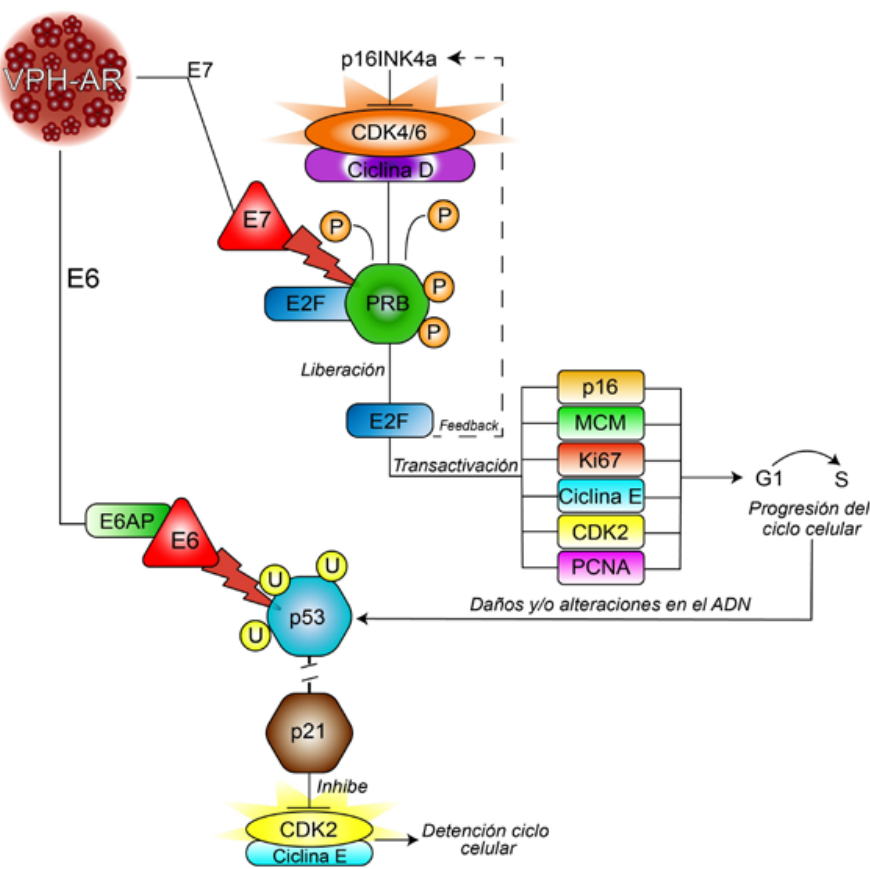

Figura 3. Esquema comparativo de la regulación del ciclo celular en una célula normal no infectada (A) versus una célula infectada por VPH-AR (B). En una célula no infectada las proteínas supresoras de tumores pRb y p53 regulan la proliferación celular, mientras que en las células con infección transformadora por la acción del VPH-AR, las oncoproteínas E6 y E7 desregulan los puntos de control de la proliferación celular, inhibiendo el mecanismo de control de p53 y pRb, respectivamente. Imagen elaborada por las autoras 
la proteína $\mathrm{pRb}$ en la fase $\mathrm{G} 1$, fosforilación que genera un cambio conformacional en $\mathrm{pRb}$, el cual induce la liberación del factor de transcripción E2F, que al ser liberado genera la transactivación de los genes que codifican para las proteínas involucradas en la replicación del ADN (MCM, Ki-67, ciclina E, CDK2, PCNA), lo que facilita el inicio de la fase de síntesis del ADN. Pero cuando se inhibe el estado proliferativo, la proteína $\mathrm{pRb}$ se encuentra en un estado hipofosforilado y se activa su función inhibitoria sobre el factor de transcripción E2F, lo que bloquea la replicación del ADN (Doorbar, et al., 2012). Las condiciones fisiológicas normales que permiten las transiciones del ciclo celular proliferativo a uno no proliferativo están, a su vez, comandadas por la proteína inhibitoria p16, la cual aumenta su expresión y se une de forma específica al complejo CDK4/ CDK6, inhibiendo indirectamente la fosforilación de la $\mathrm{pRb}$ $\mathrm{y}$, por lo tanto, estimulando su estado hipofosforilado y su unión al factor E2F, lo que evita que la célula mantenga el estado proliferativo continuo. En la figura 3 también se evidencia cómo la célula cuenta con un mecanismo que se activa en caso de que se detecte alguna alteración o daño, o un aumento inusual de la proliferación celular. Esta segunda vía de protección de la célula esta comandada por la proteína p53, la cual se activa como respuesta al daño del ADN y se acumula en la célula generando, así, la detención del ciclo celular. El aumento de la p53 induce la transcripción de la p21, la cual se encarga, a su vez, de inhibir el complejo ciclina $\mathrm{E} / \mathrm{CDK} 2$, lo que genera que la $\mathrm{pRb}$ permanezca en un estado hipofosforilado que le permite permanecer unida a E2F bloqueando su función. En las infecciones transformadas por VPH-AR los puntos de control del ciclo celular se ven alterados, primero porque la oncoproteína E7 bloquea e induce la degradación de $\mathrm{pRb}$, de tal manera que el factor E2F queda libre, dando paso a la transcripción de los genes de la fase de síntesis. Consiguientemente, la proteína p16 es regulada positivamente, tratando de inhibir la proliferación descontrolada, pero allí su función inhibitoria es nula dado que el aumento de E2F no está relacionado con un aumento del complejo CDK4/6 (Doorbar, et al., 2012). En segundo lugar, como respuesta a esta alteración, la célula normalmente induce la expresión de $\mathrm{p} 53$, pero este control también se ve alterado en una célula transformada por VPH-AR dado que la oncoproteína E6 induce la degradación de p53 (Scheffner, et al., 1993). De esta manera, en las infecciones oncogénicas y persistentes de genotipos del VPH-AR se observa un aumento del nivel de p16 en presencia de proteínas indicadoras de proliferación celular tales como Ki67 y MCM, proteínas nucleares que son detectadas concomitantemente en las fases de proliferación del ciclo celular como consecuencia de la actividad oncogénica de la oncoproteína E7 (Doorbar, et al., 2012).

Hipótesis de la relación entre la filogenia y la oncogénesis del VPH, una visión translacional. Se ha demostrado que la variabilidad genética del VPH explica su capacidad oncogénica (Schiffman, et al., 2005). Esta mayor capacidad oncogénica de ciertos genotipos y variantes moleculares reside, a su vez, en las diferencias funcionales de las oncoproteínas E6 y E7 (Münger \& Howley, 2002) y la variabilidad genética del huésped (Doorbar, 2018). Específicamente, la proteína E6 del VPH 16, no solo tiene mayor afinidad por la proteína p53, sino que, además, algunas de sus variantes degradan más eficientemente la proteína supresora de tumores. También se ha observado un mayor riesgo de cáncer cervical en mujeres infectadas con variantes específicas, asociación que parece estar influenciada por el componente ancestral del huésped (Lopera, et al., 2014). Estas características genéticas del virus y del huésped, además, se ven influenciadas por estilos de vida que afectan la exposición de los individuos a factores hormonales, tales como el uso de los anticonceptivos orales, los múltiples partos o el consumo del tabaco (Luhn, et al., 2013). Por lo tanto, los mecanismos moleculares que controlan el ciclo celular y que se alteran debido a las diferencias funcionales en E6 y E7 explicarían el por qué solo una pequeña proporción de individuos entre los millones que se infectan con el VPH desarrollan el cáncer y, además, el hecho de ser la fuente de posibles biomarcadores predictores de su desarrollo.

Las pruebas basadas en las secuencias genómicas de los VPH-AR y los genotipos VPH16 y 18 predicen el riesgo de cáncer. Una vez confirmado el papel etiológico del VPH en el cáncer cervical y el hallazgo de los casi 40 tipos que infectan el epitelio genitourinario y que son transmitidos sexualmente, se ha observado que solo 14 tipos son oncogénicos, lo cual llevó a diseñar pruebas que diferenciaran molecularmente los VPH-AR de los VPH-BR. En la actualidad se cuenta con, por lo menos, 193 técnicas moleculares disponibles comercialmente para la detección de los VPH-AR, 69 de las cuales han sido clínicamente evaluadas (Burd, 2016). Dichas pruebas pueden dividirse en tres grupos principales según si detectan: 1) el ADN de los VPH-AR sin discriminar entre tipos virales, es decir, solo detectan la presencia o ausencia de los VPH-AR; 2) el ADN de los VPH-AR con la concomitante genotipificación de algunos de los principales tipos de alto riesgo, y 3) el ARNm (ARN mensajero) de las oncoproteínas E6 y E7 de los VPH-AR. Estas pruebas tienen una sensibilidad cercana al $100 \%$ para detectar lesiones potencialmente malignas del cuello uterino, y en ensayos clínicos controlados aleatorizados se ha demostrado que, en una primera ronda de tamización, dichas pruebas no solo detectan más lesiones $\mathrm{NIC} 2+$ y NIC3+ que la citología, el método tradicional de detección, sino que, además, ayudan a reducir el número de casos y muertes por cáncer cervical hasta en un $70 \%$, ya que permiten determinar el tratamiento inmediato en las mujeres con mayor riesgo (Denny, et al., 2017). Sin embargo, la prueba de VPH-AR es poco específica, pues la mayoría de las mujeres positivas para VPH-AR tienen infecciones transitorias que se resuelven espontáneamente (Rodríguez, et al., 2008). 
Los estudios sobre la historia natural del VPH han demostrado que el riesgo de lesiones de alto grado y de cáncer cervical varía sustancialmente según el tipo de VPHAR; el VPH16 es el tipo más prevalente en el cáncer, seguido del VPH18. El $70 \%$ de la carga mundial de cáncer cervical se atribuye a la infección por estos dos tipos virales (de Sanjose, et al., 2010). Como ya se mencionó, las pruebas de VPH-AR son inespecíficas, pero el riesgo de lesiones de alto grado en mujeres infectadas por el VPH16 o el VPH1 8 es mayor que el asociado con la infección por cualquiera de los otros genotipos de VPH-AR. Por esta razón, la tipificación del VPH16 y el VPH18 ya se usa en la clínica en dos circunstancias principales: 1) para el triaje de mujeres de 21 años o más con resultados de ASC-US en la citología cervical, y 2) para el triaje de mujeres mayores de 30 años positivas en la tamización con la prueba de VPH-AR. En ambos casos, los resultados de la tipificación permiten detectar a las mujeres que deben ser enviadas a colposcopia inmediatamente (Burd, 2016). Las guías clínicas de Estados Unidos ya han adoptado estas estrategias e incorporan la citología cervical combinada con la tipificación de VPH16/18 como estrategia de triaje para mujeres de 25 años o más (Saslow, et al., 2012).

Tamización con la prueba de VPH-AR. La prueba de VPH ha sido ampliamente validada en diferentes ensayos clínicos que han incluido cerca de 140.000 mujeres a nivel mundial. Esta evidencia se resumió en una revisión sistemática de la literatura en la cual se concluyó que la prueba de VPH es más sensible que la citología para la tamización de cáncer cervical en la población general y después del tratamiento (Koliopoulos, et al., 2017; van der Heijden, et al., 2015).

En la guía de práctica clínica colombiana para la detección y manejo de lesiones precancerosas de cuello uterino del 2014 (No. GPC 2014 - 44) y en la Resolución № 3280 de 2018, se recomendó la tamización basada en pruebas de ADN-VPH y el triaje con citología cervical en mujeres a partir de los 30 años (Ministerio de Salud y Protección Social, 2014). Las pruebas recomendadas en esta guía según los grupos de edad son las siguientes.

- De los 25 a los 30 años: citología de cuello uterino bajo el esquema 1-1-3 (una citología cada año durante dos años consecutivos; si el resultado de las dos es negativo se hace cada tres años).

- De los 30 a los 65 años: prueba de VPH y triaje con citología. Se recomienda que las mujeres negativas para VPH se repitan la prueba en un intervalo de cinco años; las mujeres positivas deben recibir triaje con citología y si los resultados de esta son positivos, deben ser referidas a colposcopia y biopsia según el tipo de hallazgos; a las mujeres con resultado negativo en el triaje debe recomendárseles una nueva prueba de VPH a los 18 meses, con el fin de evaluar si persiste la infección.

- De los 25 a los 50 años en mujeres residentes en zonas de difícil acceso a servicios de salud: técnicas de inspección visual del cuello uterino (Ministerio de Salud y Protección Social, 2014).
El uso de estas técnicas de tamización ha sido objeto de estudio a nivel nacional e internacional, y se han descrito algunas de sus ventajas y desventajas. Entre las ventajas de la citología cervicouterina se encuentra su alta especificidad y aceptación entre las mujeres. Sin embargo, tiene una sensibilidad baja, cercana al 53 \% (Baena, et al., 2017), lo que quiere decir que muchas lesiones se pasan por alto y las mujeres no son diagnosticadas correctamente.

En cuanto a la prueba de VPH, se sabe que tiene una alta sensibilidad y alto valor predictivo negativo, por lo que no debe hacerse muchas veces durante la vida. Si la prueba es negativa deberá repetirse a los 5 años, lo que a su vez disminuye la carga económica para el sistema de salud. Sin embargo, la prueba tiene poca especificidad, lo que implica que muchas mujeres tendrán un resultado positivo, pero ello no necesariamente implica una lesión en el cérvix. En la mayoría de estas mujeres, especialmente las menores de 30 años, la infección remite sin ninguna consecuencia en el curso de los 18 meses siguientes (Rodríguez, et al., 2008). Esto conlleva la necesidad de pruebas diagnósticas adicionales, como colposcopias y biopsias innecesarias, que constituyen una carga económica para el sistema.

Por otra parte, una de las ventajas de la inspección visual con ácido acético (VIA) es que no requiere personal altamente especializado ni equipos costosos, y facilita el tratamiento o el diagnóstico confirmatorio inmediato de las mujeres positivas, especialmente en áreas rurales y de difícil acceso, pues solo se requiere una visita a la clínica. Sin embargo, para hacer esta prueba el personal debe recibir entrenamiento y debe hacerse un control de calidad para garantizar el uso correcto de la técnica (Castle, et al., 2017), la cual tiene una especificidad moderada (83 \%) (Gaffikin, et al., 2003); además, es probable que sea menos precisa en las mujeres posmenopáusicas y depende de un evaluador (American Society for Colposcopy and Cervical Pathology - ASCCP, 2013).

Los biomarcadores son pruebas confiables, relativamente baratas, que por su carácter molecular no dependen de un evaluador. Desempeñan un papel fundamental en la correcta clasificación de las mujeres positivas para el VPH. Su uso permite restringir la remisión a colposcopia y biopsia a aquellas mujeres con un verdadero riesgo de tener lesiones precancerosas que requieren tratamiento inmediato. De esta manera se optimiza un mejor uso de los recursos, se disminuyen el diagnóstico incorrecto o equívoco y los tratamientos innecesarios.

Las proteínas celulares p16 y ki67, la detección de VPH16/18 y la detección de microARN (miARN) pueden ser biomarcadores de la transformación maligna útiles en el triaje. La infección maligna por el VPH-AR induce proliferación celular sostenida por la acción de la proteína E7 sobre la pRb. Esta acción conlleva la expresión de la Ki67, una proteína nuclear que participa y es marcador indicativo de procesos de proliferación celular. En condiciones normales esta proliferación irregular y, consecuentemente, la expresión de Ki67 es controlada por el inhibidor de la 
cinasa dependiente de la ciclina $\mathrm{p} 16$, una proteína supresora de tumores, la cual inhibe la proliferación celular al activar una cascada de eventos celulares para que la $\mathrm{pRb}$ se una e inactiva la E2F, la proteína central inductora de la transcripción de proteínas relacionadas con la proliferación celular. En el caso de la infección por VPH-AR, sin embargo, debido a la ausencia de la pRb, la p16 no solo no logra su capacidad antitumoral, sino que, además, se acumula en presencia de ki67, lo cual indica una desregulación aberrante del ciclo celular.

En varios estudios se ha demostrado que la prueba que detecta la p16 y la Ki 67 tiene más sensibilidad que la citología convencional para la detección de $\mathrm{NIC} 2+$ en mujeres positivas para el VPH. En este artículo se han referenciado específicamente los estudios en la población de la "EPS Kaiser Permanente de Estados Unidos" (Wentzensen, et al., 2015) y el Primary ASC-US LSIL Marker Study (PALMS) de Francia (Bergeron, et al., 2015), porque incluyeron un mayor número de mujeres durante un periodo de seguimiento más prolongado y una apropiada verificación de las pruebas de referencia (colposcopia y biopsias en todas las mujeres del estudio). El hallazgo más claro de estos estudios es que, a diferencia de la citología convencional, que necesita seguimiento anual, la prueba de p16/Ki67 permite ampliar de manera segura hasta por tres años el seguimiento de mujeres positivas para VPH que aún no han presentado lesiones de alto grado (Clarke, et al., 2018). Por otro lado, la identificación concomitante de los VPH 16 y 18 en mujeres positivas para VPH ha demostrado ser una alternativa muy precisa para detectar de forma inmediata quienes necesitan colposcopia, aunque es importante mencionar que solo el $50 \%$ de las lesiones de alto grado son positivas para estos dos tipos virales, lo que deja de lado casi al $50 \%$ de mujeres con lesiones de alto grado que requieren pruebas con otros biomarcadores para la identificación y el adecuado manejo clínico (Castle, et al., 2011).

Además, se sabe que durante el desarrollo del cáncer cervical ocurre una cascada de eventos anormales que altera el control del ciclo celular e induce la perturbación de la respuesta inmunitaria antitumoral, alteración la expresión génica y procesos epigenéticos como la metilación y la desregulación de los microARN (miARNA), y que estos marcadores pueden ser útiles en el diagnóstico y el tratamiento del cáncer cervical (Kori \& Yalcin-Arga, 2018). Esta revisión se centra en biomarcadores evaluados en nuestro laboratorio, pero es importante señalar que hay una gran cantidad de biomarcadores que estan siendo evaluados y que en un futuro cercano podrán ser alternativas para el manejo clínico de mujeres positivas para el VPH en todo el mundo.

\section{Materiales y métodos}

Participantes y muestras cervicales. La población de estudio incluyó a 864 mujeres entre los 20 y los 69 años que habían sido referidas a colposcopia en instituciones médicas de Medellín por presentar una citología anormal ( $\geq$ ASCUS) o una prueba de VPH positiva.
Antes de la colposcopia, se recolectó una muestra de exfoliado cervical usando el citocepillo Rovers CervexBrush ${ }^{\circledR}$ (Rovers, Oss, The Netherlands), la cual fue almacenada en $20 \mathrm{~mL}$ del medio de transporte ThinPrep ${ }^{\circledR}$ PreservCyt ${ }^{\circledR}$ (Hologic Inc., Marlborough, MA, USA) y usada para la detección de VPH y para la tinción dual de p16/ki67. Posteriormente, un ginecólogo hizo la colposcopia y la toma de biopsias de los sitios acetoblancos con sospecha de lesiones cervicales; además, se tomó una biopsia aleatoria con el fin de detectar lesiones que no eran visibles. La muestra de exfoliado cervical se transportó al laboratorio del Grupo de Infección y Cáncer de la Universidad de Antioquia, donde se realizó la detección de VPH usando la prueba Cobas ${ }^{\circledR} 4800$ (Roche Diagnostics, Mannheim, Germany), así como la tinción dual para las proteínas p16 y ki67 con la prueba CINtec ${ }^{\circledR}$ PLUS kit (Ventana, Tucson, Arizona, USA). Las biopsias cervicales se enviaron a los laboratorios de patología que prestaban el servicio a cada uno de los centros de colposcopia y de allí se obtuvieron los informes histopatológicos.

Detección de VPH-AR y tipificación VPH16/18 (Cobas ${ }^{\circledR}$ 4800). Se utilizó la prueba comercial Cobas 4800 aprobada por la Food and Drug Administration (FDA) para la detección de 14 tipos de VPH-AR, la cual identifica específicamente los tipos de VPH 16 y 18 y detecta simultáneamente los otros doce tipos virales (VPH 31, 33, $35,39,45,51,52,56,58,59,66$ y 68 ) como un solo grupo denominado VPH-AR. El ADN se aisló usando el sistema automático Cobas X 480 a partir de la muestra de exfoliado cervical obtenida en medio Preservcyt ${ }^{\circledR}$. Enseguida, se detectó el ADN viral mediante la amplificación de una secuencia de 200 pares de bases de la región L1 del genoma del VPH y del gen $H B B$ de la $\beta$-globina humana mediante la amplificación de una secuencia de 330 pares de bases usada como control interno para la validación de la extracción. Se utilizaron sondas TaqMan ${ }^{\circledR}$, marcadas con cuatro diferentes fluoróforos, para la detección de los productos amplificados durante la reacción en cadena de la polimerasa (polymerase chain reaction, $\mathrm{PCR}$ ) en tiempo real, la cual se hizo en el termociclador Cobas Z 480. Por último, los resultados se interpretaron con el programa Cobas 480 como "negativos", "positivos para VPH-16", "positivos para VPH-18", "positivos para otros VPH-AR" o como la combinación de los tres últimos.

Detección de las proteínas p167 y ki67. Para la tinción inmunocitoquímica se utilizó el estuche comercial CINtec ${ }^{\circledR}$ PLUS aprobada por el Invima, con el cual se determina cualitativamente y de forma simultánea la expresión de las proteínas p16INK4a y Ki-67 en extendidos de células cervicales. En la detección se empleó un anticuerpo monoclonal primario producido en ratón (clon $\mathrm{E} 6 \mathrm{H} 4^{\mathrm{TM}}$ ) y un anticuerpo monoclonal primario producido en conejo (clon 274-11 AC3), dirigidos contra las proteínas p16 y Ki-67, respectivamente. Posteriormente, se usó un sistema de revelado basado en dos reactivos de polímeros conjugados: 
el primero con fragmentos Fab de anticuerpos anti-ratón conjugados con peroxidasa de rábano picante, y el segundo con fragmentos $\mathrm{Fab}$ de anticuerpos anti-conejo conjugados con fosfatasa alcalina de rábano picante. A continuación, se llevaron a cabo las reacciones de revelado mediante la transformación del cromógeno 3'3 diaminobencidina (DAB) mediado por la peroxidasa de rábano picante y la transformación de un cromógeno Fast Red mediado por la fosfatasa alcalina.

Las tinciones se clasificaron dicotómicamente como positivas para p16 o Ki-67 (presencia de tinción dual) o negativas para p16 o Ki-67 (ausencia de tinción), conforme al atlas y la guía del fabricante. La prueba se consideró positiva cuando se observaba por lo menos una célula con un citoplasma marrón (p16) y un núcleo rojo (Ki-67), es decir, se debían detectar las dos tinciones simultáneamente en la misma célula. Si no se observaban células cervicales epiteliales con ambas tinciones, la prueba se consideraba negativa. La presencia de células cervicales epiteliales con inmunorreacción frente a uno solo de los dos marcadores indicaba que estas no eran positivas, incluso si ambos tipos de células cervicales se encontraban en la misma muestra. Todas las tinciones fueron evaluadas bajo microscopio de luz por un patólogo del Departamento de Patología de la Facultad de Medicina de la Universidad de Antioquia.

Predicción mediante algoritmos bioinformáticos de microARN. Con el objetivo de escoger un panel con buena probabilidad de ser utilizado como biomarcador para la detección de lesiones de alto grado de cérvix en mujeres infectadas con VPH-AR, se hizo una predicción mediante algoritmos bioinformáticos de los microARN diana reguladores de proteínas blanco de la acción de E6 y E7 del VPH usando la similitud de secuencias y la estabilidad termodinámica del programa miRWalk2.0 (Dweep \& Gretz, 2015). Como estrategia de predicción se emplearon los códigos EntrezID (National Center for Biotechnology Information, NCBI) de 19 proteínas diana de la acción de E6 y E7 de VPH-AR; los resultados obtenidos en la predicción se filtraros seleccionando los microARN reportados previamente en la literatura científica. Acto seguido, se filtraron los microARN descritos con expresión aberrante en artículos relacionados con lesiones preneoplásicas y cáncer cervical y, por último, se seleccionaron aquellos con sobrerregulación.

Diagnóstico histológico. El diagnóstico de las biopsias tomadas el día del reclutamiento de las participantes se hizo por colposcopia. Las biopsias se colocaron inmediatamente en formalina tamponada y se enviaron para ser procesadas y leídas en los laboratorios de patología que prestaban el servicio a cada centro de colposcopia.

Consideraciones éticas. A todas las mujeres se les explicó el estudio y quienes estuvieron de acuerdo en participar dieron su consentimiento por escrito autorizando el uso de las muestras y los datos. Las mujeres recibieron una copia del consentimiento informado. El estudio fue aprobado por el Comité de Bioética para Investigación en Humanos de la Sede de Investigación Universitaria de la Universidad de Antioquia (CBE-SIU), según consta en el acta número 14-40-536 del 2014.

\section{Resultados}

La positividad para VPH16 y 18 y p16 y ki67 diferencia a las mujeres positivas para NIC1 y NIC2 en la prueba de $\boldsymbol{V P H}-\boldsymbol{A R}$. En los análisis llevados a cabo en nuestro laboratorio (Tabla 1), se observó que los resultados positivos aumentaron con ambas pruebas a medida que aumentaba la gravedad de las lesiones cervicales. En la prueba de VPH16/18 la positividad fue de 11,44, 19,28, 56,67, $46,43,57,14$ y $75 \%$ en mujeres con diagnóstico negativo de NIC1, NIC2, NIC3, carcinoma escamocelular invasivo y adenocarcinoma, respectivamente. En la de p16/ki67 la positividad también aumentó con la gravedad de la lesión, pasando de $11,25 \%$ en las mujeres con diagnóstico negativo a $100 \%$ en los casos de cáncer escamocelular invasivo. En las mujeres positivas para ambas pruebas, VPH-AR y

Tabla 1. Positividad para VPH-AR, VPH 16/18, p16/ki67 y p16/ki67/VPH-AR de acuerdo al diagnóstico histopatológico cervical.

\begin{tabular}{|c|c|c|c|c|c|c|c|c|}
\hline \multirow[t]{2}{*}{$\begin{array}{l}\text { Diagnóstivo } \\
\text { histológico }\end{array}$} & \multicolumn{2}{|c|}{$\begin{array}{l}\text { VPH-AR } \\
\text { Positivo }^{\text {a }}\end{array}$} & \multicolumn{2}{|c|}{$\begin{array}{c}\text { VPH 16/18 } \\
\text { Positivo }^{b}\end{array}$} & \multicolumn{2}{|c|}{$\begin{array}{l}\text { p16/ki67 } \\
\text { Positivo }\end{array}$} & \multicolumn{2}{|c|}{$\begin{array}{c}\text { p16/ki67/VPH-AR } \\
\text { Positivo }^{\mathrm{a}}\end{array}$} \\
\hline & $\mathbf{n}$ & $\%$ & $\mathbf{n}$ & $\%$ & $\mathbf{n}$ & $\%$ & $\mathbf{n}$ & $\%$ \\
\hline Negativo $(n=542)$ & 236 & 43,54 & 62 & 11,44 & 61 & 11,25 & 40 & 7,38 \\
\hline NIC1 (n=223) & 148 & 66,37 & 43 & 19,28 & 52 & 23,32 & 41 & 18,39 \\
\hline $\operatorname{NIC} 2(n=60)$ & 53 & 88,33 & 34 & 56,67 & 19 & 31,67 & 18 & 30 \\
\hline NIC3 $(n=28)$ & 25 & 89,29 & 13 & 46,43 & 19 & 67,86 & 18 & 64,29 \\
\hline $\operatorname{SCC}(n=7)$ & 6 & 85,71 & 4 & 57,14 & 7 & 100 & 6 & 85,71 \\
\hline $\mathrm{ADC}(\mathrm{n}=4)$ & 3 & 75 & 3 & 75 & 3 & 75 & 2 & 50 \\
\hline Total $(n=864)$ & 471 & 54,51 & 159 & 18,4 & 161 & 18,63 & 125 & 14,47 \\
\hline
\end{tabular}

${ }^{\text {a }}$ Positivo para cualquier tipo de VPH-AR (VPH16, 18, 31, 33, 35, 39, 45, 51, 52, 56, 58, 59, 66 y 68).

${ }^{b}$ Positivo para cualquier tipo de VPH 16 y/o 18

${ }^{c}$ Prueba de VPH Positiva para cualquiera de los 14 tipos de alto riesgo y p16/ki67 positivas 
p16/ki67, se observó que solo el 7,38 \% de aquellas sin lesiones dio positivo, en la de NIC1 solo el 18,39\%, en tanto que para las lesiones de alto grado y cáncer la positividad fue del 30 al $86 \%$. Por lo tanto, estas pruebas no solo podrían aumentar la probabilidad de detectar lesiones de alto grado, sino que disminuirían el número de mujeres que deben ser referidas para colposcopia o sometidas a un tratamiento innecesario, pues clasifican correctamente a las mujeres positivas para VPH que tienen lesiones de alto grado (datos aún no publicados). Estos resultados son preliminares y deben ser validados en estudios con un mayor tamaño de muestra y en una situación de tamización.

Los microARN que controlan las proteínas del ciclo celular blanco de la acción y desreguladas por las oncoproteínas E6 y E7 son biomarcadores de inducción de lesiones malignas del cérvix. Los microARN son un grupo de ARN no codificantes de 19 a 23 nucleótidos conservados evolutivamente, cuya función es la regulación postranscripcional y tranduccional. Los microARN intervienen en muchos procesos celulares, entre los que se encuentran la diferenciación y la proliferación celular, el desarrollo y la apoptosis (Turchinovich, et al., 2011). Puesto que bloquea la expresión de genes inhibidores de la proliferación (supresores de tumores), la desregulación de los miARN puede llevar a una pérdida del control del ciclo celular, lo que se ha asociado con subsecuentes alteraciones génicas al promover la progresión y la metástasis (Turchinovich, et al., 2011). Hay evidencias preliminares in vitro sobre la modulación de la expresión de los microARN por los oncoproteínas E6 y E7 del VPH-AR (Harden \& Munger, 2017). En el cáncer cervical, la expresión diferencial de los microARN en lesiones precursoras de bajo y alto grado se ha relacionado con el proceso carcinogénico inducido, como se muestra en la figura 4 , debido al bloqueo de la actividad de proteínas supresoras de tumores tales como la p53, la CDKN1A (p21), la CDKN1B (p27), la PRB-E2F1, la CUL2, la EP300 y la UBR4, inducido por las oncoproteínas E6 y E7 de VPH-AR, lo que constituye un paso clave en la carcinogénesis cervical. Esto se ve ha visto respaldado indirectamente por los ensayos in vitro que demuestran la correlación entre la sobrerregulación de los microARN que modulan la expresión de las proteínas reguladoras del ciclo celular y la expresión de E6 y E7 in vitro (Harden \& Munger, 2017). Otros hallazgos que respaldan indirectamente esta posible relación incluyen la regulación de p53 por miR106b, miR-16, miR-18 y miR-25; de CDKN1A (p21) por miR-106b, miR-15b, miR-16, miR-20b; de CDKN1B (p27) por miR-155; de E2F1 por miR-106b, miR-181b, miR-205, miR-20b y miR-10a; de UBR4 por miR-378a, miR-155, CUL2 por miR-15b y miR-16, y de EP300 por miR-181b, miR-25 (Figura 4), así como por el hecho de que algunos de estos microARN están sobreexpresados en las lesiones cervicales de alto grado y en el cáncer cervical.

En este contexto, mediante los algoritmos de predicción bioinformática se identificó un set de 41 microARN

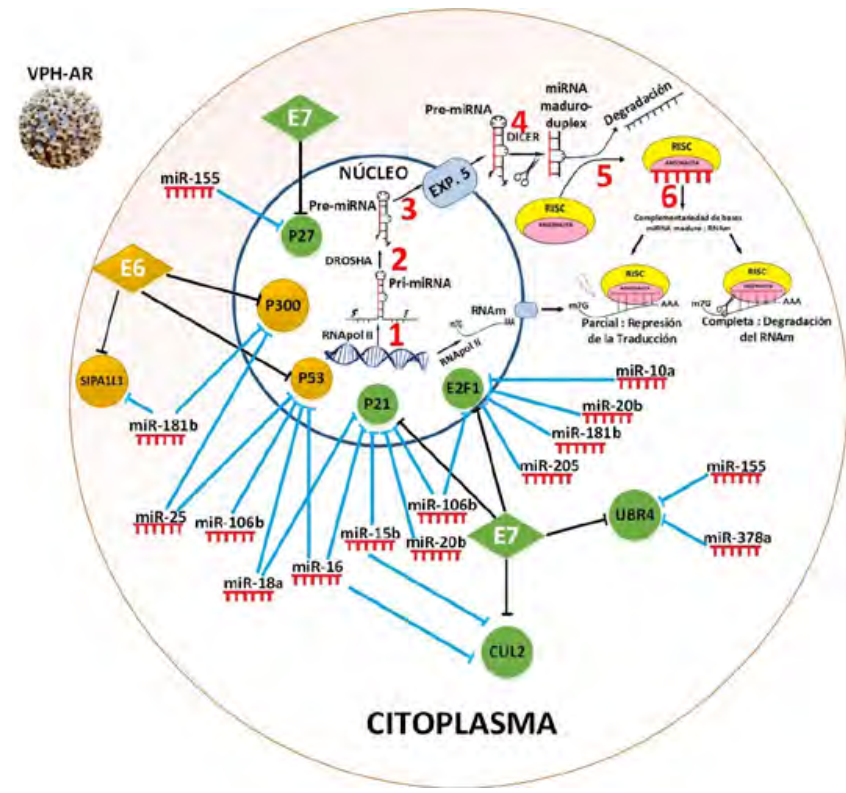

Figura 4. Biogénesis y función de los miARN en el contexto de una célula infectada por VPH de alto riesgo

Los miRNAs se transcriben en el núcleo por la RNA pol II generando largos transcritos de miRNA primario llamados pri-miRNA, los cuales contienen una caperuza 7-metil guanosina en el extremo 5' y una cola poliA en el extremo 3'. Los pri-miARN son clivados por la RNasa III (enzima endoribonucleasa), llamada también Drosha, dando lugar a intermediarios (pre-miRNA) con aproximadamente 70 nucleótidos. Los pre-miRNA son exportados al citoplasma a través de la proteína transmembranal nuclear exportina 5, luego son clivados por otra RNasa III llamada Dicer, dando lugar a un RNA de doble cadena de 19 a 25 nucleótidos, que se disocia por acción helicasa; cada cadena es un miARN, sin embargo, uno es degradado y el otro, que proviene de la cadena guía, es funcional $\mathrm{y}$ es incorporado en el complejo de silenciamiento inducido por el ARN (RISC), compuesto, a su vez, por proteínas argonautas (16). El complejo RISC-miARN se dirige a sus ARNm dianas y se une a los sitios complementarios, si la complementariedad de bases entre miARN y ARNm es completa, se degrada el transcrito y si es parcial, hay represión de la traducción.

La expresión de las oncoproteínas E6 y E7 (rombos) en una célula infectada por VPH-AR, desregula los niveles de proteínas supresoras tumorales (círculos) importantes en el controlar el ciclo celular (la desregulación se representa con rayas negras), y a su vez se induce la sobrexpresión de los miARN que reprimen la expresión de las mismas proteínas (la represión se representa con rayas azules). Imagen elaborada por las autoras.

potencialmente desregulados por las proteínas E6 y E7 de VPH-AR. Ocho de ellos regularon la expresión de las proteínas p53, EP300, CDK1A y CDK1B, involucradas en la carcinogénesis del cáncer cervical (datos no publicados). Los microARN poseen propiedades deseables en comparación con otros biomarcadores, son altamente estables frente a la acción de las ribonucleasas, lo que facilita su detección no invasiva en fluidos corporales, y son muy estables tanto in vivo como in vitro (Glinge, et al., 2017). En varios estudios se ha postulado una cantidad apreciable de potenciales 
microARN desregulados en lesiones preneoplásicas y en cáncer (Li \& Hu, 2015). Nuestra hipótesis es que aquellos miARN relacionados con la función de las oncoproteínas E6 y E7 tienen mejor potencial como marcadores para la estratificación de las mujeres con mayor riesgo de presentar lesiones cervicales de alto grado.

\section{Conclusiones}

El VPH tiene un componente genético que le ha permitido evolucionar de forma concertada con el huésped, y es por esto que, a pesar de que anualmente millones de personas son infectadas por este virus, son muy pocas las que llegan a desarrollar un cáncer por esta causa. La relación evolutiva entre la filogenia viral, la ascendencia del huésped y los mecanismos moleculares que se desregulan como consecuencia de la exposición a otros factores como el tabaco, el uso de anticonceptivos hormonales y los múltiples partos, determinan el bajo porcentaje de mujeres con infección por los VPH-AR cuya persistencia puede resultar en cáncer cervical.

El reconocimiento de los VPH-AR como agentes causales del cáncer cervical, el estudio de la historia natural de la enfermedad, y la biología molecular del virus y su interacción con la célula infectada, han permitido conocer los mecanismos de la oncogénesis del virus, entre los cuales se destacan los relacionados con la sobreexpresión de las oncoproteínas virales E6/E7 de VPH-AR. La especificidad de la relación de estas proteínas virales con las de su huésped ocasiona la pérdida del control del ciclo celular y la acumulación de errores genéticos que conducen a la aparición del cáncer. No sorprende, entonces, que, hasta la fecha, los biomarcadores con mejor desempeño para la detección de lesiones de cérvix de alto grado sean las proteínas E6 o E7 y su blanco de acción. A pesar de que este conocimiento ha impulsado el estudio y el desarrollo de técnicas moleculares basadas en la detección de biomarcadores proteicos, aquellos basados en procesos epigenéticos y ácidos nucléicos ofrecen ventajas no solo por ser más estables sino porque, además, su detección sería más precisa y consistente mediante ensayos más simples y menos costosos. En este sentido, es importante resaltar que la determinación de los mecanismos moleculares y celulares básicos de los procesos patogénicos es fundamental para su establecimiento y su traducción en estrategias efectivas de prevención.

La principal limitación del presente estudio es el carácter preliminar de sus resultados, ya que deben ser evaluados en una situación de tamización y con un mayor tamaño de muestra para así evaluar el desempeño diagnóstico de cada uno de los marcadores. Sin embargo, teniendo en cuenta las recomendaciones internacionales, estos resultados respaldan la utilidad de este tipo de estudios sobre la correlación entre la tendencia de la tasa de positividad del biomarcador y el grado de la lesión cervical para evaluar su valor clínico como herramienta de tamización en el cáncer cervical (Arbyn, et al., 2009; Stanczuk, et al., 2017).

\section{Contribución de los autores}

Arianis Tatiana Ramírez-Pineda: revisión del estado del arte sobre la detección de p16/Ki67, los mecanismos moleculares de oncogénesis del VPH y los biomarcadores de cáncer cervical; elaboración del primer borrador del manuscrito. Martha Isabel González: análisis para la identificación de microARN como potenciales biomarcadores de detección de lesiones potencialmente malignas de cérvix. Kelly Melisa Castañeda Vanegas: evaluación y revisión del estado del arte en torno de la genotipificación del VPH16/18 como biomarcador para la detección de lesiones potencialmente malignas de cérvix. María Cecilia Agudelo-Fernández: revisión del estado del arte sobre la utilidad clínica de los biomarcadores y redacción y de la escritura del manuscrito. Carolina López-Urán: lectura de las placas para la tinción inmunocitoquímica de p16/ki67 y revisión del manuscrito. Gloria Inés Sánchez-Vásquez: evaluación de biomarcadores para la detección de lesiones potencialmente malignas de cérvix en mujeres positivas para VPH-AR; hipótesis del estudio; planeación y organización del contenido; escritura de los aspectos básicos de la filogenia y variabilidad genética del VPH y su relación con el componente ancestral del huésped y la patogenia del VPH; revisión, corrección y aval final del manuscrito.

\section{Conflicto de intereses}

Los autores no tienen conflictos de intereses.

\section{Referencias}

Antinore, M. J., Birrer, M. J., Patel, D., Nader, L., McCance, D. J. (1996). The human papillomavirus type 16 E7 gene product interacts with and trans-activates the AP1 family of transcription factors. EMBO J. 15 (8): 1950-1960. https:// www.ncbi.nlm.nih.gov/pubmed/8617242

Arbyn, M., Ronco, G., Cuzick, J., Wentzensen, N., Castle, P. E. (2009). How to evaluate emerging technologies in cervical cancer screening? Int J Cancer. 125 (11): 2489-2496. Doi:10.1002/ijc. 24774

Baena, A., Guevara, E., Almonte, M., Arias-Stella, J., Sasieni, P., Sánchez, G. I. (2017). Factors related to inter-observer reproducibility of conventional Pap smear cytology: A multilevel analysis of smear and laboratory characteristics. Cytopathology. 28 (3): 192-202. Doi: 10.1111/cyt.12410

Bergeron, C., Ikenberg, H., Sideri, M., Denton, K., Bogers, J., Schmidt, D., .. . Ridder, R. (2015). Prospective evaluation of p16/Ki-67 dual-stained cytology for managing women with abnormal Papanicolaou cytology: PALMS study results. Cancer Cytopathol. 123 (6): 373-381. Doi: 10.1002/ cncy. 21542

Bergeron, C., Ronco, G., Reuschenbach, M., Wentzensen, N., Arbyn, M., Stoler, M., von Knebel Doeberitz, M. (2015). The clinical impact of using p16(INK4a) immunochemistry in cervical histopathology and cytology: An update of recent developments. Int J Cancer. 136 (12): 2741-2751. Doi: $10.1002 /$ ijc. 28900

Berumen, J., Ordóñez, R. M., Lazcano, E., Salmerón, J., Galván, S. C., Estrada, R. A., ... Madrigal-de la Campa, 
A. (2001). Asian-American variants of human papillomavirus 16 and risk for cervical cancer: A case-control study. J Natl Cancer Inst. 93 (17): 1325-1330. DOI: 10.1093/ jnci/93.17.1325

Bosch, F. X., Lorincz, A., Munoz, N., Meijer, C. J., Shah, K. V. (2002). The causal relation between human papillomavirus and cervical cancer. J Clin Pathol. 55 (4): 244-265. DOI: 10.1136/jcp.55.4.244

Bray, F., Ferlay, J., Soerjomataram, I., Siegel, R. L., Torre, L. A., Jemal, A. (2018). Global cancer statistics 2018: GLOBOCAN estimates of incidence and mortality worldwide for 36 cancers in 185 countries. CA Cancer J Clin. Doi: $10.3322 /$ caac. 21492

Burd, E. M. (2016). Human papillomavirus laboratory testing: The changing paradigm. Clin Microbiol Rev. 29 (2): 291319. Doi: $10.1128 /$ CMR.00013-15

Burk, R. D., Harari, A., Chen, Z. (2013). Human papillomavirus genome variants. Virology. 445 (1-2): 232-243. Doi:10.1016/j.virol.2013.07.018

Burk, R. D., Terai, M., Gravitt, P. E., Brinton, L. A., Kurman, R. J., Barnes, W. A., . . . Hildesheim, A. (2003). Distribution of human papillomavirus types 16 and 18 variants in squamous cell carcinomas and adenocarcinomas of the cervix. Cancer Res. 63 (21): 7215-7220. DOI: 14612516/ Cancer Res.2003-09

Castle, P. E., Murokora, D., Perez, C., Alvarez, M., Quek, S. C., Campbell, C. (2017). Treatment of cervical intraepithelial lesions. Int J Gynaecol Obstet. 138 (Suppl 1): 20-25. Doi:10.1002/ijgo.12191

Castle, P. E., Stoler, M. H., Wright, T. C., Sharma, A., Wright, T. L., Behrens, C. M. (2011). Performance of carcinogenic human papillomavirus (HPV) testing and HPV16 or HPV18 genotyping for cervical cancer screening of women aged 25 years and older: A subanalysis of the ATHENA study. Lancet Oncol. 12 (9): 880-890. Doi:10.1016/S14702045(11)70188-7

Clarke, M. A., Cheung, L. C., Castle, P. E., Schiffman, M., Tokugawa, D., Poitras, N., . . . Wentzensen, N. (2018). Five-year risk of cervical precancer following p16/ki-67 dual-stain triage of HPV-positive women. JAMA Oncol. Doi:10.1001/jamaoncol.2018.4270

Colombian Ministry of Health (Ministerio de Salud y Protección Social). [Clinical Practice Guide (CPG) for the detection and management of precancerous cervical lesions]. In: Colombian Ministry of Health editor. Guia No GPC 2014-44. Bogota, Colombia.

Cornet, I., Gheit, T., Clifford, G. M., Combes, J. D., Dalstein, V., Franceschi, S.,...Clavel, C. (2013). Human papillomavirus type 16 E6 variants in France and risk of viral persistence. Infect Agent Cancer. 8 (1): 4. Doi:10.1186/1750-9378-8-4

Cornet, I., Gheit, T., Franceschi, S., Vignat, J., Burk, R. D., Sylla, B. S., . . . Clifford, G. M. (2012). Human papillomavirus type 16 genetic variants: phylogeny and classification based on E6 and LCR. J Virol. 86 (12): 68556861. Doi:10.1128/jvi.00483-12

Cornet, I., Gheit, T., Iannacone, M. R., Vignat, J., Sylla, B. S., Del Mistro, A., . . . Clifford, G. M. (2013). HPV16 genetic variation and the development of cervical cancer worldwide. Br J Cancer. 108 (1): 240-244. Doi:10.1038/ bjc. 2012.508 de Boer, M. A., Peters, L. A., Aziz, M. F., Siregar, B., Cornain, S., Vrede, M. A., . . . Fleuren, G. J. (2004). Human papillomavirus type $16 \mathrm{E} 6, \mathrm{E} 7$, and L1 variants in cervical cancer in Indonesia, Suriname, and The Netherlands. Gynecol Oncol. 94 (2): 488-494. Doi:10.1016/j.ygyno.2004.05.037

de Sanjose, S., Quint, W. G., Alemany, L., Geraets, D. T., Klaustermeier, J. E., Lloveras, B., . . . Group, R. I. S. a. H. T. T. S. (2010). Human papillomavirus genotype attribution in invasive cervical cancer: A retrospective cross-sectional worldwide study. Lancet Oncol. 11 (11): 1048-1056. Doi:10.1016/S1470-2045(10)70230-8

de Villiers, E. M., Fauquet, C., Broker, T. R., Bernard, H. U., zur Hausen, H. (2004). Classification of papillomaviruses. Virology. 324 (1): 17-27. Doi:10.1016/j.virol.2004.03.033

Denny, L., de Sanjose, S., Mutebi, M., Anderson, B. O., Kim, J., Jeronimo, J., . . . Sankaranarayanan, R. (2017). Interventions to close the divide for women with breast and cervical cancer between low-income and middle-income countries and high-income countries. Lancet. 389 (10071): 861-870. Doi:10.1016/S0140-6736(16)31795-0

Doorbar, J. (2018). Host control of human papillomavirus infection and disease. Best Pract Res Clin Obstet Gynaecol. 47: 27-41. Doi: 10.1016/j.bpobgyn.2017.08.001

Doorbar, J., Egawa, N., Griffin, H., Kranjec, C., Murakami, I. (2015). Human papillomavirus molecular biology and disease association. Rev Med Virol, 25 Suppl 1, 2-23. Doi: 10.1002/rmv.1822

Doorbar, J., Quint, W., Banks, L., Bravo, I. G., Stoler, M., Broker, T. R., Stanley, M. A. (2012). The biology and lifecycle of human papillomaviruses. Vaccine. 30 (Suppl 5): F55-70. Doi:10.1016/j.vaccine.2012.06.083

Dweep, H., \& Gretz, N. (2015). miRWalk2.0: a comprehensive atlas of microRNA-target interactions. Nat Methods. 12 (8): 697. Doi: 10.1038/nmeth.3485

Eroschenko, V. P. (2008). Atlas of histology with functional correlation, female reproductive system. (Eleventh edition ed.). Philadelphia: Lippincott Williams \& Wilkins.

Finnen, R. L., Erickson, K. D., Chen, X. S., Garcea, R. L. (2003). Interactions between papillomavirus L1 and L2 capsid proteins. J Virol. 77 (8): 4818-4826. https://www. ncbi.nlm.nih.gov/pubmed/12663788.

Gaffikin, L., Lauterbach, M., Blumenthal, P. D. (2003). Performance of visual inspection with acetic acid for cervical cancer screening: A qualitative summary of evidence to date. Obstet Gynecol Surv. 58 (8): 543-550. Doi: 10.1097/01.ogx.0000079632.98372.26

Glinge, C., Clauss, S., Boddum, K., Jabbari, R., Jabbari, J., Risgaard, B., . . . Tfelt-Hansen, J. (2017). Stability of Circulating Blood-Based MicroRNAs - Pre-Analytic Methodological Considerations. PLoS One. 12 (2): e0167969. Doi:10.1371/journal.pone.0167969

Harden, M. E., \& Munger, K. (2017). Human papillomavirus 16 E6 and E7 oncoprotein expression alters microRNA expression in extracellular vesicles. Virology. 508: 63-69. Doi: 10.1016/j.virol.2017.05.005

Herfs, M., Yamamoto, Y., Laury, A., Wang, X., Nucci, M. R., McLaughlin-Drubin, M. E., . . . Crum, C. P. (2012). A discrete population of squamocolumnar junction cells implicated in the pathogenesis of cervical cancer. Proc Natl Acad Sci USA. 109 (26): 10516-10521. Doi: 10.1073/ pnas. 1202684109 
Hildesheim, A., Schiffman, M., Bromley, C., Wacholder, S., Herrero, R., Rodriguez, A., . . . Burk, R. D. (2001). Human papillomavirus type 16 variants and risk of cervical cancer. J Natl Cancer Inst. 93 (4): 315-318.

Koliopoulos, G., Nyaga, V. N., Santesso, N., Bryant, A., MartinHirsch, P. P., Mustafa, R. A., . . . Arbyn, M. (2017). Cytology versus HPV testing for cervical cancer screening in the general population. Cochrane Database Syst Rev, 8, Cd008587. Doi: 10.1002/14651858.CD008587.pub2

Kori, M., \& Yalcin Arga, K. (2018). Potential biomarkers and therapeutic targets in cervical cancer: Insights from the meta-analysis of transcriptomics data within network biomedicine perspective. PLoS One. 13 (7): e0200717. Doi: 10.1371/journal.pone.0200717

Li, M. Y., \& Hu, X. X. (2015). Meta-analysis of microRNA expression profiling studies in human cervical cancer. Med Oncol. 32 (6): 510. Doi: 10.1007/s12032-015-0510-5

Lopera, E. A., Baena, A., Flórez, V., Montiel, J., Duque, C., Ramírez, T., . . . Sánchez, G. I. (2014). Unexpected inverse correlation between Native American ancestry and Asian American variants of HPV16 in admixed Colombian cervical cancer cases. Infect Genet Evol. 28: 339-348. Doi: 10.1016/j.meegid.2014.10.014

Luhn, P., Walker, J., Schiffman, M., Zuna, R. E., Dunn, S. T., Gold, M. A., . . . Wentzensen, N. (2013). The role of co-factors in the progression from human papillomavirus infection to cervical cancer. Gynecol Oncol. 128 (2): 265270. Doi: 10.1016/j.ygyno.2012.11.003

Mirabello, L., Yeager, M., Cullen, M., Boland, J. F., Chen, Z., Wentzensen, N., . . . Schiffman, M. (2016). HPV16 Sublineage associations with histology-specific cancer risk using hpv whole-genome sequences in 3200 women. J Natl Cancer Inst. 108 (9): 108-116. Doi: 10.1093/jnci/djw100

Muñoz, N., Bosch, F. X., de Sanjosé, S., Herrero, R., Castellsagué, X., Shah, K. V., . . . Group, I. A. f. R. o. C. M. C. C. S. (2003). Epidemiologic classification of human papillomavirus types associated with cervical cancer. N Engl J Med. 348 (6): 518-527. Doi: 10.1056/ NEJMoa021641

Muñoz, N., Castellsagué, X., de González, A. B., Gissmann, L. (2006). Chapter 1: HPV in the etiology of human cancer. Vaccine. 24 (Suppl 3): S3/1-10. Doi: 10.1016/j. vaccine.2006.05.115

Münger, K., \& Howley, P. M. (2002). Human papillomavirus immortalization and transformation functions. Virus Res. 89 (2): 213-228.

Pim, D., \& Banks, L. (2010). Interaction of viral oncoproteins with cellular target molecules: Infection with high-risk vs low-risk human papillomaviruses. Apmis. 118 (6-7): 471493. Doi: 10.1111/j.1600-0463.2010.02618.x

Rodríguez, A. C., Schiffman, M., Herrero, R., Wacholder, S., Hildesheim, A., Castle, P. E., . . . Burk, R. (2008). Rapid clearance of human papillomavirus and implications for clinical focus on persistent infections. Journal of the National Cancer Institute. 100 (7): 513-517. Doi: 10.1093/ jnci/djn044

Rodríguez, A. C., Schiffman, M., Herrero, R., Wacholder, S., Hildesheim, A., Castle, P. E., . . . Group, P. E. G. (2008). Rapid clearance of human papillomavirus and implications for clinical focus on persistent infections. J Natl Cancer Inst. 100 (7): 513-517. Doi: 10.1093/jnci/djn044
Roman, A., \& Munger, K. (2013). The papillomavirus E7 proteins. Virology. 445 (1-2): 138-168. Doi:10.1016/j. virol.2013.04.013

Sanchez, G. I., Kleter, B., Gheit, T., van Doorn, L. J., de Koning, M. N., de Sanjosé, S., . . . Quint, W. G. (2011). Clinical evaluation of polymerase chain reaction reverse hybridization assay for detection and identification of human papillomavirus type 16 variants. J Clin Virol. 51 (3): 165-169. Doi: 10.1016/j.jcv.2011.03.013

Saslow, D., Solomon, D., Lawson, H. W., Killackey, M., Kulasingam, S. L., Cain, J., . . Pathology, A. S. f. C. (2012). American Cancer Society, American Society for Colposcopy and Cervical Pathology, and American Society for Clinical Pathology screening guidelines for the prevention and early detection of cervical cancer. Am J Clin Pathol. 137 (4): 516-542. Doi: 10.1309/ AJCPTGD94EVRSJCG

Scheffner, M., Huibregtse, J. M., Vierstra, R. D., Howley, P. M. (1993). The HPV-16 E6 and E6-AP complex functions as a ubiquitin-protein ligase in the ubiquitination of p53. Cell. 75 (3): 495-505.

Schiffman, M., Herrero, R., Desalle, R., Hildesheim, A., Wacholder, S., Rodriguez, A. C., . . Burk, R. D. (2005). The carcinogenicity of human papillomavirus types reflects viral evolution. Virology. 337 (1): 76-84. Doi: 10.1016/j. virol.2005.04.002

Stanczuk, G. A., Baxter, G. J., Currie, H., Forson, W., Lawrence, J. R., Cuschieri, K., . . . Arbyn, M. (2017). Defining optimal triage strategies for hrhpv screen-positive women-an evaluation of HPV 16/18 genotyping, cytology, and p16/Ki-67 cytoimmunochemistry. Cancer Epidemiol Biomarkers Prev. 26 (11): 1629-1635. Doi: 10.1158/10559965.epi-17-0534

Tornesello, M. L., Duraturo, M. L., Salatiello, I., Buonaguro, L., Losito, S., Botti, G., . . . Buonaguro, F. M. (2004). Analysis of human papillomavirus type-16 variants in Italian women with cervical intraepithelial neoplasia and cervical cancer. J Med Virol. 74 (1): 117-126. Doi: 10.1002/ jmv.20154

Turchinovich, A., Weiz, L., Langheinz, A., Burwinkel, B. (2011). Characterization of extracellular circulating microRNA. Nucleic Acids Res. 39 (16): 7223-7233. Doi: 10.1093/nar/ gkr254

van der Heijden, E., Lopes, A. D., Bryant, A., Bekkers, R., Galaal, K. (2015). Follow-up strategies after treatment (large loop excision of the transformation zone (LLETZ)) for cervical intraepithelial neoplasia (CIN): Impact of human papillomavirus (HPV) test. Cochrane Database Syst Rev. 1: Cd010757. DOI: 10.1002/14651858. CD010757.pub2

Van Doorslaer, K. (2013). Evolution of the papillomaviridae. Virology. 445(1-2): 11-20. Doi: 10.1016/j.virol.2013.05.012

Vande Pol, S. B., \& Klingelhutz, A. J. (2013). Papillomavirus E6 oncoproteins. Virology. 445 (1-2): 115-137. Doi: 10.1016/j. virol.2013.04.026

Vargas-Robles, D., Magris, M., Morales, N., de Koning, M. N. C., Rodríguez, I., Nieves, T., . . . Domínguez-Bello, M. G. (2018). High rate of infection by only oncogenic human papillomavirus in Amerindians. mSphere. 3 (3). Doi: 10.1128/mSphere.00176-18 
Walboomers, J. M., Jacobs, M. V., Manos, M. M., Bosch, F. X., Kummer, J. A., Shah, K. V., . . . Muñoz, N. (1999). Human papillomavirus is a necessary cause of invasive cervical cancer worldwide. J Pathol. 189 (1): 12-19. Doi: $\quad 10.1002 /($ SICI)1096-9896(199909)189:1<12::AIDPATH431>3.0.CO;2-F

Wentzensen, N., Fetterman, B., Castle, P. E., Schiffman, M., Wood, S. N., Stiemerling, E., . . . Kinney, W. (2015). p16/Ki-67 Dual stain cytology for detection of cervical precancer in HPV-positive women. J Natl Cancer Inst. 107 (12): djv257. Doi: 10.1093/jnci/djv257
Yamada, T., Manos, M. M., Peto, J., Greer, C. E., Munoz, N., Bosch, F. X., Wheeler, C. M. (1997). Human papillomavirus type 16 sequence variation in cervical cancers: A worldwide perspective. J Virol. 71 (3): 2463-2472.

Yeo-Teh, N. S. L., Ito, Y., \& Jha, S. (2018). High-Risk human papillomaviral oncogenes E6 and E7 target key cellular pathways to achieve oncogenesis. In Int J Mol Sci. 19.

Zsemlye, M. (2013). LSIL: Definition and management. Obstet Gynecol Clin North Am. 40 (2): 283-289. Doi: 10.1016/j. ogc.2013.03.008 